\title{
Artin Hindoglu'nun 1831 baskılı Dictionnaire Abrégé Français-Turc adlı sözlüğü
}

Yakup YILMAZ1

Neslihan CARUS²

\begin{abstract}
APA: Yılmaz, Y.; Carus, N. (2019). Artin Hindoglu'nun 1831 baskılı Dictionnaire Abrégé FrançaisTurc adlı sözlüğü. RumeliDE Dil ve Edebiyat Araştırmaları Dergisi, (Ö5), 104-111. DOI: 10.29000/rumelide.606099.
\end{abstract}

\section{$\ddot{\mathbf{O} z}$}

Codex Cumanicus metinlerinden günümüze, Transkripsiyon metinleri önemlerini hep korumuştur. $\mathrm{Bu}$ metinler sözlüklerden ve gramer kitaplarından oluşmaktadır. Her biri kelimelerin telaffuzu itibariyle değerlidir. Bu çalışmada Artin Hindoglu'nun hazırladığı Dictionnaire Abrégé FrançaisTurc ya da Osmanlı Türkçesi adıyla Hazine-yi Lüğāt adlı sözlük tanıtılacak, özellikleri ve önemi anlatılacaktır. Hindoglu, Dictionnaire Abrégé Français-Turc adlı eserini oryantalistlerin ihtiyacını karşılamak için hazırladığını ifade eder. Eseri, çeşitli Türkçe sözlükler ve gramerleri inceleyerek hazırlayan Hindoglu'nun eser planlaması şöyledir: Künyeli iç kapak I. sayfada, künyesiz iç kapak II. sayfada, boşluk III. sayfada, ithaf IV. sayfada, boşluk V. sayfada, önsöz VI-VII sayfada, kitapta kullanılan işaretler VIII. sayfada, kısaltmalar IX. sayfada yer almaktadır. Sözlükte yer alan madde başları aşağıdaki sırayla verilmiştir: A 1-39. s., B 39-62. s., C 62-140. s., D 140-193. s., E 193-248. s., F 248-278. s., G 278-300. s., H 301-312. s., I 312-336. s., J 337-341. s., K 341-341. s., L 341-355. s., M 355-384. s., N 385-392. s., O 392-400. s., P 400-446. s., Q 446-449. s., R 449-486. s., S 487-516. s., T 516-540.s., U 540-541.s., V 541-555. s., X 555. s., Y 555. s., Z 555. s. Kelime madde başlarından sonra özel adlar şu şekilde sıralanmıştır: A 556-557. s., B 557. s., C 557-558. s., D 558. s., E 558. s., F 558. s., G 558-559. s., H 559. s., I 559. s., J 559. s., K 559. s., L 559-560. s., M 560. s., N 560. s., O 560. s., P 560. s.,R 561. s., S 561. s., T 561. s., V 561-562. s. Ayrıca 503-504. sayfalarda doğru yanlış cetveli bulunmaktadır.

Anahtar kelimeler: Sözlük, Artin Hindoglu, Türkçe, Fransızca.

\section{Artin Hindoglu's Dictionnaire Abrégé Français-Turc (1831 printed)}

\begin{abstract}
From the Codex Cumanicus texts to the present day, transcription texts have always been important. These texts consist of dictionaries and grammar books. Each is valuable in terms of the pronunciation of words. In this article, Dictionnaire Abrégé Français-Turc or Ottoman Turkish by Hazīne-yi Lügāàt, which is prepared by Artin Hindoglu, will be introduced and its features and importance will be explained. Hindoglu states that Dictionnaire Abrégé Français-Turc was prepared to meet the needs of orientalists. His work, various Turkish dictionaries and grammars prepared by preparing the work of Hindus work is as follows: Inner cover on the front of page I on page 3, space III. on page, dedicating IV. on page V., on page VI-VII, the marks used in the book VIII. on the page, abbreviations

1 Doç. Dr., Kırklareli Üniversitesi, Fen Edebiyat Fakültesi, Türk Dili ve Edebiyatı Bölümü (Kırklareli, Türkiye), yilmazyakupbey@gmail.com, ORCID ID: 0000-0001-6230-8850 [Makale kaylt tarihi: 12.06.2019-kabul tarihi: 18.08.2019; DOI: 10.29000/rumelide.606099]

2 YL Öğrencisi, Kırklareli Üniversitesi, Sosyal Bilimler Enstitüsü, Türk Dili ve Edebiyatı ABD (Kırklareli, Türkiye), carusneslihan@gmail.com.
\end{abstract}


IX. is on page. The headings in the dictionary are given in the following order: A 1-39. p., B 39-62. p., C 62-140. p., D 140-193. p., E 193-248. s, F 248-278. p., G 278-300. p., H 301-312. p., I 312-336. p., J 337-341. p., K 341-341. s, L 341-355. p., M 355-384. pp. 385-392. p., 392-400. p., P 400-446. p., Q 446-449. pp. 449-486. pp. 487-516. pp. 516-540.s., U 540-541.s., V 541-555. p., X 555. p., Y 555. p., Z 555. p. After the beginning of the word, the special names are listed as follows: A 556-557. p., B 557. p., C 557-558. s, D 558. p., E 558. p., F 558. p., G 558-559. S, H 559. p., 559. p., J 559. p., K 559. p., L 559-560. s, M 560. p., N 560. p., 560. p., 560. p., R 561. p., 561. p., 561. pp, V 561-562. s. Also 503504. The pages have the correct wrong ruler.

Key words: Dictionary, Artin Hindoglu, Turkish, French.

\section{Giriş}

Türklerin çeşitli sebeplerle Batıya doğru olan göçleri, onları yeni yurtlar edinmeye, yeni yurtlarda devletler kurmaya sevk etmiştir.

Göçler sonucunda Avrupa halkları ve devletleriyle yakınlaşan Türkler, Hristiyan din adamlarının hedefleri arasına girmiş ve böylece ortaya Türkleri ve dillerini tanıtmayı amaçlayan eserler kaleme alınmaya başlamıştır. Türkleri Hristiyanlaştırmak hedefine yönelik olarak Hristiyan din adamlarınca kaleme alınan ilk eserlerden biri Codex Cumanicus olmuştur.

Avrupalıların Türkleri ve onların dillerini tanıması çoklukla Hristiyan din adamları vasıtasıyla olmuştur. CC'den sonra hazırlanan çok sayıda transkripsiyon metni de Hristiyan din adamları ve bunların misyoner olanları tarafından hazırlanmıştır.

\section{Artin Hindoglu:}

Artin Hindoglu Kütahya'da 1780 yılında doğmuş, 1795 yllında İstanbul'a gelmiş, on yll sonra da buradan Venedik'e geçmiş, 1812 yllına dek San Lazzaro adasında bir kilisede eğitim almış, Ermenice, Fransızca, İngilizce öğrenip 1817-18 yıllarında Viyana’ya geçmiş, burada Almanca öğrenmiş, Viyana'da 1824-31 yılları arasında Türkçe öğretmenliği ve İmparatorluk Yüksek Mahkemesi’nde tercümanlık yapmıştır. 1840 yılında Viyana'da öldüğü sanılır (Ertaş, 2016, s. 153)

Artin Hindoglu’nun eserleri şöyle sıralanabilir (Ertaş, 2016, s. 153):

1. Fransızca izahlı Türkçe öğreten bir kitaptır, eserin adı, basıldığı yer ve baskı tarihi hakkında herhangi bir bilgiye ulaşlamamıştır.

2. Haza Kitab-ı Sarf ve Lügat-ı Türki / Theoretisch-praktische Türkische Sprachlehre für Deutsche: Almanca izahlı Türkçe öğreten bir gramer kitabı, 1829 yılında Viyana'da basılmıştır.

3. Deutsch-Armenische Sprachlehre (Almanca-Ermenice Gramer): Almanca öğreten bir kitap, 1830 yllında Venedik'te Mığhitaristlere ait matbaada basılmıştır

4. Dictionnaire Abrege Français-Turc veya Hazine-i Lügat: Fransızca-Türkçe sözlüktür. 1831 yllında Viyana'da basılan bu sözlük, modern anlamda kaleme alınan ilk Fransızca-Türkçe sözlük olarak kabul edilmektedir (Ertaş, 2016, s. 153). 
5. Haza Kitab-ı Sarf-ı Türki / Grammaire Theorique Et Pratique de la Langue Turke, Telle Qu'elle Est Parlee a Constantinople (İstanbul'da Konuşulan Türk Dilinin Teorik ve Uygulamah Dilbilgisi): 1834 yllında Paris’te neşrettiği bir gramer kitabıdır.

6. Hazine-yi Lügat veya Dictionnaire Abrege Turc-Français: 1838 (ilk baskısı 1831) yllında Viyana'da basılmış Türkçe-Fransızca bir sözlüktür.

\section{Dictionnaire Abrégé Français-Turc ya da Hazine-yi Lügāt}

Artin Hindoglu'nun Hazine-yi Lügât adlı sözlüğü için ilk Fransızca-Türkçe sözlük ibaresi geçse (Ertaş, 2016, s. 153) de bundan önce Preindl'ın gramerinin ardında bulunan kapsamlı sözlüğü anmak gerekir (Preindl J. , 1790). Ancak sistemli ve telaffuzu isabetli sözlüklerin başında gelir.

Sayfa numaraları ilk kısma yazılmamış olsa da Romen rakamıyla belirlediğimiz sayfa sırası şöyle olmalıdır: Künyeli iç kapak I. sayfada, künyesiz iç kapak II. sayfada, boşluk III. sayfada, ithaf IV. sayfada, boşluk V. sayfada, önsöz VI-VII sayfada, kitapta kullanılan işaretler VIII. sayfada, kısaltmalar IX. sayfada yer almaktadır.

Künyeli iç kapak: Eserin adı Dictionnaire Abrégé Français-Turc ou Hazine-yi Lügàt olarak yazlı olup alt satırında müellif adı Artin Hindoglu ve bu adın altında Küçük Asya'dan Kütahya'nın yerlisi, Türk ve Ermeni dilleri öğretmeni ifadeleri yazılıdır. Sonra yayın yeri olarak Vienne (Viyana) ve 1831 tarihi bulunur.

Künyesiz iç kapak: Bu kapakta eser ve müellif adıyla yetinilmiştir.

İthaf sayfası: "Avusturyalı devlet adamı, İmparatorluk azası ve subay Baron Jean Wezlar de Plankenstern'e ithaftır." ifadesiyle başlayan bu bölümün devamında "Lütfen bu kitabı, eski öğrencim olarak ve her zaman onur duyduğum nezaketten dolayı, Türkçedeki bilginizden ilham alan saygının bir ifadesi olarak kabul edin." ifadesi ve altında da "çok mütevazı ve size adanmış yazar" diyerek ithaf yazısını bitirir.

Önsöz: Bu sayfadan önce boş bir sayfa vardır. Sözlüğün madde başına kadar olan kısmında sayfa numarası konmamıştır. Önsöz kısmında müellif, şunlardan bahsetmiştir:

Fransızca-Türkçe sözlüğünün bir ihtiyaç olduğunu, uzun zamandır bu ihtiyacı karşlamak istediğini, Avrupa'nın Osmanlı'daki değişmeleri takip ettiğini ve geliştiğini, sözlük yazmak için önünde Mozin ve François d'Alberti de Villeneuve adlı iki başrahibin yazdığı sözlük örneklerinin bulunduğunu, özellikle gramer ve telaffuzun yoruma dayalı olduğunu; Küçük Asya diye adlandırdığı Anadolu'da doğduğunu, İstanbul'da 10 yll, Viyana'da 13 yll geçirdiğini, teknik terimleri de burada eklediğini, Meninski'den yararlandığını, tıp ve botanik terimlerini, halen Mısır hidivinin özel hekimi olan Resden’in ErmeniceLatince-İtalyanca-Fransızca-Rumca-Farsça-Arapça-Türkçe sözlüğünden aldığını, yaptığı çalışmaların kendisini tanıttığını, eserindeki telaffuzun İstanbul'da kullanılan en iyi telaffuz olduğunu ifade ve iddia edip kitabının ikinci baskısı için destek bekler ve önsözü bitirir.

Bu kitapta kullanılan harflerin karşılıkları: Bu bölümde transkripsiyon harfleri ve bunların telaffuzdaki karşılıkları olan sesler verilmiş, Fransızcadan örneklerle beslenmiştir. 


\begin{tabular}{|l|l|l|l|}
\hline transkripsiyon & telaffuz & transkripsiyon & telaffuz \\
\hline ay: & ay & h & h \\
\hline dj & c & k & k , k \\
\hline e & é, i & qh & h \\
\hline é & é, i & tj & ç \\
\hline ê & e & y & $\mathrm{y}$, i, i \\
\hline gh & $\dot{\mathrm{g}}$ & & \\
\hline
\end{tabular}

Kısaltmalar: Sözlükte kullanılan kısaltmalar bu bölümde verilmiştir.

\begin{tabular}{|c|c|c|c|}
\hline $\begin{array}{l}\text { a. adjectif ou arabe (sıfat, } \\
\text { Arapça) }\end{array}$ & pl. pluriel (çokluk) & $\begin{array}{l}\text { T. terme technique } \\
\text { (teknik terim) }\end{array}$ & $\begin{array}{l}\text { v. r. verbe réciproque } \\
\text { (iştaş fiil) }\end{array}$ \\
\hline ad. adverbe (zarf) & pr. pronom (zamir) & v. voyez (bakınız) & $\begin{array}{l}\text { * figurément (mecaz } \\
\text { anlamll) }\end{array}$ \\
\hline f. feminin (müennes) & prp. préposition (takı) & $\begin{array}{l}\text { v. a. verbe actif (etken } \\
\text { fiil) }\end{array}$ & $\begin{array}{l}\text { - un sign, ou il faut répéter } \\
\text { le mot dont on parle } \\
\text { (konuşulanın tekarı) }\end{array}$ \\
\hline fa. familier (benzer) & $\begin{array}{l}\text { p. u. peu usité (az } \\
\text { kullanilmış) }\end{array}$ & $\begin{array}{l}\text { v. a. et } \mathbf{n} \text {. verbe actif et } \\
\text { neutre (etken ve edilgen } \\
\text { fiil) }\end{array}$ & $\begin{array}{l}\text { ï on n'appuie pas sur cette } \\
\text { voyelle (bu ünlüyü baskıll } \\
\text { okumuyoruz) }\end{array}$ \\
\hline m. masculin (müzekker) & q. quelqu'un (birisi) & $\begin{array}{l}\text { v. i. verbe impersonel } \\
\text { (mechul fiil) }\end{array}$ & \\
\hline $\begin{array}{l}\text { n. c. nouvelle créance } \\
\text { (yeni alıntı kelime) }\end{array}$ & $\begin{array}{l}\text { qc. quelque chose (bir } \\
\text { şey) }\end{array}$ & $\begin{array}{l}\text { v. n. verbe neutre } \\
\text { (edilgen fiil) }\end{array}$ & \\
\hline p. participe (sıfat-fiil) & s. substantif (asli) & $\begin{array}{l}\text { v. n. et a. verbe neutre et } \\
\text { actif (edilgen ve etken fiil) }\end{array}$ & \\
\hline
\end{tabular}

\section{Sözlükte madde başı kelimeler ve özellikleri}

Artin Hindoglu'nun hazırladığı Dictionnaire Abrégé Français-Turc ya da Osmanlı Türkçesi adıyla Hazine-yi Lügāat adlı sözlüğün 1938 baskısı üzerinde daha önce Yavuz Kartallığlu tarafından bir inceleme yapılmıştır (Kartallıŏlu, 2018). Ancak bu çalışma eserin 1831 tarihli ilk baskısı esas alınarak yazılmıştır.

Sözlükte yer alan madde başları aşağıdaki sayfa sırayla verilmiştir: A 1-39. s., B 39-62. s., C 62-140. s., D 140-193. s., E 193-248. s., F 248-278. s., G 278-300. s., H 301-312. s., I 312-336. s., J 337-341. s., K 341-341. s., L 341-355. s., M 355-384. s., N 385-392. s., O 392-400. s., P 400-446. s., Q 446-449. s., R 449-486. s., S 487-516. s., T 516-540.s., U 540-541.s., V 541-555. s., X 555. s., Y 555. s., Z 555. s.

Kelime madde başlarından sonra özel adlar aşağıdaki sayfa sırayla verilmiş̧ir: A 556-557. s., B 557. s., C 557-558. s., D 558. s., E 558. s., F 558. s., G 558-559. s., H 559. s., I 559. s., J 559. s., K 559. s., L 559560. s., M 560. s., N 560. s., O 560. s., P 560. s.,R 561. s., S 561. s., T 561. s., V 561-562. s.

Sözlükte yer alan madde başlarının adedi aşağıdaki gibidir: 


\section{Kelimeler}

\begin{tabular}{|l|l|l|l|l|}
\hline A- 1.139 & F- 844 & K- 1 & P- 1.409 & U- 38 \\
\hline B- 758 & G- 629 & L- 440 & Q- 94 & V- 441 \\
\hline C- 2.157 & H- 360 & M- 912 & R- 957 & X- 3 \\
\hline D- 1.330 & I- 711 & N- 240 & S- 905 & Y- 4 \\
\hline E- 1.385 & J- 145 & O- 281 & T- 658 & Z-11 \\
\hline
\end{tabular}

Toplam 15.852 madde başı kelime yer alır.

\section{Özel adlar}

\begin{tabular}{|l|l|l|l|l|}
\hline A- 48 & F- 3 & K- 7 & P- 15 & Z- 5 \\
\hline B- 9 & G- 9 & L- 15 & Q- 7 & \\
\hline C- 32 & H- 8 & M- 21 & S- 24 & \\
\hline D- 11 & I- 8 & N- 14 & T- 8 & \\
\hline E- 15 & J- 13 & O- 5 & V- 7 & \\
\hline
\end{tabular}

Toplam 240 madde başı özel ad yer alır.

\section{Sözlükte kelimelerin telaffuzları}

Transkripsiyon metinleri devrin telaffuzu merkezinde ifade eder. Artin Hindoglu eserinde kelimelerin telaffuzunu "Bu kitapta kullanılan harflerin karşıllı̆ı” başlı̆ı ile eser başında sunduğu liste istikametinde, Fransızca madde başının karşısında kısaltmalardan sonra Osmanlı Türkçesi imlası ile kelimeleri vermiş, yanına transkripsiyon işaretleriyle yazılmış telaffuzunu vermiştir. Bu telaffuzların doğruluğu dikkat çekicidir. Bazı transkripsiyon metinlerinde telaffuzlarda ağız özellikleri, tercüman veya rehberin dil yanlışları da kendini göstermektedir. Eserden şu noktalar dikkat çekicidir:

1. Osmanlı Türkçesi imlası kendisini korusa da düzleşme ya da yuvarlaklaşma meselesi telaffuzda devrin özellikleri bağlamında neredeyse ortadan kalkmıştır.

2. Yazı dili ve konuşma dili ayrılığı sözlükte bariz biçimde görülür.

3. Sözlükte vulgarize edilmiş, zaman içinde halk ağzında biçim değiştirmiş kelimeler de vardır.

4. Arapça ve Farsça kelimelerin imla ve telaffuzu çoklukla aynı kalsa da zaman içinde Türkçeleşmiş Arapça ve Farsça kelimelere de rastlanmaktadır.

5. Eski Anadolu Türkçesi devresinden kalma bazı kelimelere ve biçim özelliklerine de rastlanmaktadir.

6. Arkaik sayılabilecek, günümüzde kullanımdan düşmüş kelimeler de görülür.

\section{Türkçe kelimelerin madde başı yapılma usulü}

Eserin madde başları Fransızcadır. Bu çalışmada bizler, madde başı açıklaması olarak yer alan Türkçe açıllamaları ya da karşılıkları madde başı halinde vereceğiz. Onun da yöntemini şöyle belirledik:

osmanlı türkçesi türkiye türkçesi [< transkripsiyonlu hali fransızca karşıllı̆ı] 


\begin{tabular}{|c|c|}
\hline $\begin{array}{l}\text { A } \\
\text { üzerine üzerine [< üzérine a] (01) } \\
\text { degin değin [< déguin a] (01) } \\
\text { dek dek [< dék a] (o1) } \\
\text { sarḳıtma sarkıtma [< sarketma abaissement] (01) } \\
\text { düşüsş düşüş [< duchuch abaissement] (o1) }\end{array}$ & $\begin{array}{l}\text { B } \\
\text { hayal hayal [< qheyal babeau] (39) } \\
\text { köpecik köpekçik [< kéupédjik babiche] (39) } \\
\text { yanşaklık yanşaklık[< yanchaklek babil] (39) } \\
\text { yanşak yanşak [< yanchak babillard] (39) } \\
\text { geveze geveze [< guévézé babiller] (39) }\end{array}$ \\
\hline $\begin{array}{l}\text { C } \\
\text { hayde haydi }[<\text { haydé ça] (62) } \\
\text { bunda bunda }[<\text { bounda ça] (62) } \\
\text { buraya buraya [< bouraya ça] (62) } \\
\text { öte beri öte beri [ }<\text { éuté béri ça] (62) } \\
\text { mühr-i süleyman mühr-i süleyman }[<\text { muhrî } \\
\text { suléyman cabale] (62) }\end{array}$ & $\begin{array}{l}\text { D } \\
\text { belî evet }[<\text { béli da] (140) } \\
\text { vak'a vaka }[<\text { vaka da] (140) } \\
\text { hayr hayır }[<\text { qhayer da] (140) } \\
\text { boş boş }[<\text { boch da] (140) } \\
\text { oyuncak at oyuncak at }[<\text { oyoundjak at dada }] \\
\text { (140) }\end{array}$ \\
\hline $\begin{array}{l}\text { E } \\
\text { su su [< sou eau] (193) } \\
\text { llıca llıca [< eledja eaux] (193) } \\
\text { hamamlar hamamlar [< hamamlar eaux] (193) } \\
\text { kırpmak kırpmak [< kerpmak ébarber] (193) } \\
\text { makas ile düzetmek makas ile düzeltmek [< } \\
\text { makasilé düzétmék ébarber] (193) } \\
\text { tüylerini yolmak tüylerini yolmak [< tüylerini } \\
\text { yolmak ébarber] (193) }\end{array}$ & $\begin{array}{l}\text { F } \\
\text { mesel masal [< mésél fable] (248) } \\
\text { kıssa kıssa [kessé fable] (248) } \\
\text { karhaneci işçi, üretici [< kiarqhanédji fabricant] } \\
(248) \\
\text { yapıcı yapıcı [< yapedje fabricant] (248) } \\
\text { usta usta [< ousta fabricant] (248) }\end{array}$ \\
\hline $\begin{array}{l}\text { G } \\
\text { birinin gözünü açmak birinin gözünü açmak [< } \\
\text { birinin guéuzunu atjmak gabatine] (278) } \\
\text { tuz vergisi tuz vergisi [< touz vérguisi gabelle] } \\
\text { (278) } \\
\text { meteris sepedi ağırlık sepedi [< météris sépédi } \\
\text { gabion] (278) } \\
\text { kapı demiri kapı demiri [< kapou démiri gâche] } \\
\text { (279) } \\
\text { yă̆ dökeceği yağ dökeceği [< yagh déuyédjéyı } \\
\text { gâche] (279) }\end{array}$ & $\begin{array}{l}\text { H } \\
\text { hey hey }[<\text { héy ha] (301) } \\
\text { yazık yazık [< yazek ha] (301) } \\
\text { alımlı alımlı [< alemle habile] (301) } \\
\text { elinden gelir elinden gelir [< élindén guélir } \\
\text { habile] (301) } \\
\text { kabiliyyetli kabiliyetli [ }<\text { kabiliyetli habile] (301) }\end{array}$ \\
\hline $\begin{array}{l}\text { I } \\
\text { kara leylek kara leylek [< kara léylék ibis] (312) } \\
\text { balık tutkalı ballk tutkalı [< balek toutkale } \\
\text { ichtyocolle] (312) } \\
\text { ballk yiyen balık yiyen [< balek yéyén } \\
\text { ichtyophage] (312) } \\
\text { bunda bunda [< bounda ici] (312) } \\
\text { burda burda [< bourda ici] (312) }\end{array}$ & $\begin{array}{l}\text { J } \\
\text { kursak kursak [< koursak jabot] (337) } \\
\text { yanşamak gevezelik etmek [< yanchamak jaboter, } \\
\text { jabotter] (337) } \\
\text { ağzı durmamak ağzı durmamak [< aghze } \\
\text { dourmamak jaboter, jabotter] (337) } \\
\text { yll aşırı ekilmemiş tarla nadas [< yıl achere } \\
\text { ékilmémich tarla jachére] (337) } \\
\text { sümbül sümbül [< sumbul jacinthe] (337) }\end{array}$ \\
\hline
\end{tabular}




\begin{tabular}{|c|c|}
\hline $\begin{array}{l}\text { K } \\
\text { kermez kermes [< kermez kermes] (341) }\end{array}$ & $\begin{array}{l}\text { L } \\
\text { o o }[<\text { o la }](341) \\
\text { ol ol }[<\text { ol la }](341) \\
\text { onda onda }[<\text { onda la }](341) \\
\text { orada orada }[<\text { orada la] }(341) \\
\text { o yerde o yerde }[<\text { o yérdé la }](341)\end{array}$ \\
\hline $\begin{array}{l}\text { M } \\
\text { benim benim }[<\text { benim ma] (355) } \\
\text { benimki benimki [< benimki ma] (355) } \\
\text { makarna makarna [< makarna makaroni] (355) } \\
\text { ten zayıflatmak ten zayıflatmak [< tén } \\
\text { zayeflatmak macèrer] (355) } \\
\text { Islatmak ıslatmak [< eslatmak macérer] (355) }\end{array}$ & $\begin{array}{l}\text { N } \\
\text { bodur bodur [< bodour nabot] }(385) \\
\text { bacaksız bacaksız [< badjaksez nabot] }(385) \\
\text { koyu turuncu koyu turuncu }[<\text { koyou } \\
\text { touroundjou nacarat] (385) } \\
\text { al kirmızı [< al nacarat] (385) } \\
\text { kayık kayık [< kayek nacelle] (385) }\end{array}$ \\
\hline $\begin{array}{l}\text { O } \\
\text { hey hey [< héy o ] (392) } \\
\text { vah vah [< vah o ] (392) } \\
\text { muti olmak boyun eğmek [< muti olmak obéir] } \\
\text { (392) } \\
\text { itaat etmek itaat etmek [< itaat étmék obéir] (392) } \\
\text { söz tutmak söz tutmak [< séuz toutmak obéir] } \\
\text { (392) } \\
\text { eslemek eslemek, itaat etmek [< éslémék obéir] } \\
\text { (392) }\end{array}$ & $\begin{array}{l}\text { P } \\
\text { çayır çayır [< tjayer pacage] (400) } \\
\text { barış, sulh edicī barış, barış edici [< barech, } \\
\text { soulh édidji pacificateur] (400) } \\
\text { sus etmek yatıştırmak [< sous étmék pacifier] } \\
\text { (400) } \\
\text { barıştırmak barıştırmak [< barechtermak } \\
\text { pacifier] (400) } \\
\text { kavl söz, söz verme [< kavl pacte] (401) }\end{array}$ \\
\hline $\begin{array}{l}\text { Q } \\
\text { kırk yaşında olan kırk yaşında olan [< kerk } \\
\text { yachenda olan quadragénaire] (446) } \\
\text { kırklık kırklık [< kerklek quadragénaire] (446) } \\
\text { dört köşeli dört köşeli [< déurt kéuchéli } \\
\text { quadrangulaire] (446) } \\
\text { atlı bölüğüu atlı bölüğü [< atle béuluyu quadrille] } \\
\text { (446) } \\
\text { dört heceli dört heceli [< deurt hédjéli } \\
\text { quadrisyllabe] (446) }\end{array}$ & $\begin{array}{l}\text { R } \\
\text { sık tekrarlama sık tekrarlama [< sek tékrarlama } \\
\text { rabâchage] (449) } \\
\text { daima tekrarlamak daima tekrarlamak [< } \\
\text { dayema tekrarlamak rabâcher] (449) } \\
\text { aşağı varma alçaltma [< achaghe varma rabais] } \\
\text { (449) } \\
\text { alçaklatmak küçümsemek [<altjaklatmak } \\
\text { rabaisser] (449) } \\
\text { aşağı itmek aşağılamak [< achaghe étmék } \\
\text { rabaisser] (449) }\end{array}$ \\
\hline $\begin{array}{l}\text { S } \\
\text { kara ardıc kara ardıç [< kara ardedj sabine] (487) } \\
\text { saç ağacı saç ağacı [< satj aghadje sabine] (487) } \\
\text { kum kum [< koum sable] (487) } \\
\text { kum saati kum saati [< koum saate sable] (487) } \\
\text { ?? tibir tibir [< tibir sable] (487) } \\
\text { kum dökmek kum dökmek [< koum déukmek } \\
\text { sabler] (487) }\end{array}$ & $\begin{array}{l}\text { T } \\
\text { tütün tütün }[<\text { tutun tabao] }(516) \\
\text { enfiye enfiye [< émfiyé tabao] (516) } \\
\text { burun otu burun otu }[<\text { bournotou tabao] }(516) \\
\text { mukallid mukallit [< moukallid tabarin] }(516) \\
\text { mukallidlik mukallitlik [< moukallidlik } \\
\text { tabarinage] (516) }\end{array}$ \\
\hline
\end{tabular}




\begin{tabular}{|c|c|}
\hline kumlu kumlu [< koumlou sableux] (487) & \\
\hline $\begin{array}{l}\text { U } \\
\text { şiş şiş [< chich ulcére] (540) } \\
\text { şişirmek şişirmek [< chichirmék ulcérer] (540) } \\
\text { incitmek incitmek [< indjitmék ulcérer] (540) } \\
\text { şişmek şişmek [< chichmék ulcérer] (540) } \\
\text { öte yandaki öte yandaki [< éuté yandaki ultérieur] } \\
\text { (540) }\end{array}$ & $\begin{array}{l}\text { V } \\
\text { olsun olsun [< olsoun va] (541) } \\
\text { pek eyi pekiyi [< pék éyi va] (541) } \\
\text { mahlüllülks mahlüllük [< mahloullouk vacance] } \\
(541) \\
\text { tatil günleri tatil günleri [< téatil guunléri } \\
\text { vacance] (541) } \\
\text { boş boş }[<\text { boch vacant] }(541)\end{array}$ \\
\hline $\begin{array}{l}\text { X } \\
\text { kılıç balığı kılıç balığı [< keledj baleghe xiphias] } \\
(555) \\
\text { sarı zambak sarı zambak [< sare zambak xiphion] } \\
\text { (555) } \\
\text { öd ağacı öd ağacı [< éud aghadje xyle-aloés] (555) }\end{array}$ & $\begin{array}{l}\text { Y } \\
\text { ande onda }[<\text { andé y] }(555) \\
\text { orda orada }[<\text { orda y] (555) } \\
\text { orada orada }[<\text { orada y] (555) } \\
\text { oraya oraya }[<\text { oraya y] }(555) \\
\text { üstüne üstüne }[<\text { ustuné y] (555) }\end{array}$ \\
\hline $\begin{array}{l}\text { Z } \\
\text { gayretci gayretçi [< ghayrétdji zélateur] (556) } \\
\text { gayret gayret [< ghayrét zéle] (556) }\end{array}$ & $\begin{array}{l}\text { gayretlī gayretli [< ghayrétli zélé] (556) } \\
\text { semt-i re's başkent [< semti réés zénith] (556) } \\
\text { bad-ı saba sabah rüzgarı [< badi saba zéphir] (556) }\end{array}$ \\
\hline
\end{tabular}

\section{Sonuç}

Artin Hindoglu'nun hazırladığı Dictionnaire Abrégé Français-Turc ya da Osmanlı Türkçesi adıyla Hazine-yi Lüḡàt adlı sözlükte yer alan kelimelerin imla ve telaffuz kayıtları ortaya çıkarıldığında kelimelerin biçim değişmeleri, imla ve telaffuz farkının derecesi, bazı harflerin hangi seslerin karşılığı olduğu ve ses değişimlerinin ne derecede gerçekleştiği, o-u, ö-ü ünlülerinden hangisinin hangi kelimede bulunduğu gibi pek çok fonetik ve morfolojik sorun belli bir devir için ortadan kalkacaktır. Bu çalışmanın tamamlanması sonucunda, devrin sözvarlığına dair elde bir veri olacaktır. Sözvarlığını oluşturan kelimelerin devir bakımından hangilerinin yaygın olduğu ortaya çıacaktır.

\section{Kaynakça}

Ertaş, K. (2016). Türk Dili ve Ermeniler: Osmanlı'nın Ermeni Dilbilimcileri. JASS, Winter II(53), 151162.

Hindoglu, A. (1831). Dictionnaire Abrégé Français-Turc ou Ĥazine-yi Lüḡàt . Vienne.

Hindoglu, A. (1838). Dictionnaire Abrege Turc-Français ou Hazine-i Lügat. Vienne.

Kartallığlu, Y. (2018). Artin Hindoğlu'nun Hazine-i Lugat, Dictionnaire Turc-Français Adlı Eseri Üzerine. Dil Araşttrmaları(22), 17-26.

Preindl, J. (1790). Grammaire Turque: D'une toute nouvelle methode d'apprendre cette langue en peu de semaines avec un vocabulaire. Berlin.

Preindl, J. v. (1789). Vocabulaire de la langue turque: Berlin. 